\title{
Decay and interference theories of short-term forgetting
}

CARLTON SPRING, Department of Educational Psychology, Stanford University, Stanford, Calif. 94305

Decay and interference theories of short-term forgetting were evaluated. Length of recall interval and amount of retroactive interference were systematically varied. In order to eliminate rehearsal, incidental recall was measured. Forgetting was not affected by varying length of recall interval, but it increased as amount of interference was increased. Results are interpreted as support for an interference theory of short-term forgetting.

Peterson \& Peterson (1959) demonstrated that correct recall of single trigrams declines rapidly as the recall interval is lengthened up to $18 \mathrm{sec}$. To prevent rehearsal, Ss were required to count backwards by threes during the recall interval.

This result is compatible with a decay theory of forgetting: probability of forgetting increased as the recall interval was extended. It is also compatible, however, with a retroactive interference theory of forgetting: probability of forgetting increased as the interpolated task was extended.

Murdock (1961, Experiment 3) attempted to resolve this issue by varying the rate of the interpolated activity. He found that forgetting varied substantially with the number of interpolated items, but not with their rate of presentation. This result supports an interference theory of forgetting. His result, however, is ambiguous. A slower rate of interpolated activity might allow occasional covert rehearsals of the target item. For a fixed number of interfering items, rehearsal would be more likely for long than short recall intervals; therefore, decay due to passage of time could be cancelled due to rehearsal.

Waugh \& Norman (1965) performed a similar experiment and obtained similar results. In their task, rehearsal was difficult; moreover, Ss were instructed not to rehearse. Still, the result is ambiguous. In this experiment, a slower rate of interpolated activity allowed more time to study the target item. For a fixed number of interfering items, study time increased as the recall interval increased; therefore, decay due to passage of time could be cancelled by extra study.

The present experiment attempts to resolve the decay-versusinterference issue with an experimental design similar to those discussed above. That is, the rate of interpolated activity was systematically varied. The experiment is different, however, in that incidental memory was tested to eliminate the possibility of rehearsal; and the time available to study the target item was held constant.

In addition, the present experiment differs in another way. Murdock used words for the target as well as the interfering items. Likewise, Waugh and Norman used digits for the target as well as the interfering items. The present experiment, however, uses target and interfering items which are dissimilar. Given this dissimilarity, it should be more surprising to find that the interpolated activity interferes with retention of the target item in the sense that an $A-C$ list interferes with retention of an A-B list in paired-associate learning.

\section{METHOD}

Ss were 120 undergraduate and graduate students at Stanford University. Participation was voluntary.

Because incidental memory was tested, each $S$ participated in only one trial. Ss were instructed that a deck of cards would be dealt, one card for each beat of a metronome set at 52 beats per second-approximately one card every second. The cards were printed with a trigram, or a two-digit addition problem, or were blank. If a trigram was printed on a card, Ss read the letters immediately after it was dealt. If an addition was printed on a card, Ss computed and said the sum immediately after it was dealt. Ss were instructed to say nothing when a blank card was dealt.

After all cards were dealt, Ss were asked to recall the last trigram they had read. Thus, the last trigram was the target item, and the blank and addition cards following it were the interpolated activity. Becausc Ss werc not instructed to remember anything, there was no reason for them to rehearse the target item during the interpolated activity.

Ss were randomly divided into three groups, with $\mathbf{4 0} \mathrm{Ss}$ in each group. Different decks of cards were uscd with each group. Each deck was divided into two parts: practice and trial. The practice parts of the three decks were the same, containing 25 cards in the following sequence ( $\mathrm{T}$-trigram, $\mathrm{A}$-addition, B-blank)

\section{ABAATAATABABAAABAAAABAAAA}

The trigrams were $J B N$ and $H C X$, with Witmer association values of $25 \%$. In addition to giving Ss practice, the practice cards were intended to provide proactive interference by introducing two trigrams before the target item.

The trial parts of the three decks contained only the target trigram, FKZ, with a Witmer association value of $25 \%$. Thus, each $S$ read only three trigrams. The trial cards followed the practice cards, delayed only long enough to inform $S$ s of the change.

The first seven cards of the trial parts of the three decks were the same, and ended with the target trigram followed by a blank. These cards were: ABABATB. The remaining cards, constituting the interpolated activity, differed for each group. For Group 1 the remaining cards were: AAAAAA. For Group 2 the remaining cards were: $A B A B A B A B A B A B$. For Group 3 the remaining cards were: AAAAAAAAAAAA. If each addition is considered a unit of interference, Group 1 was given six units of interference in $6 \mathrm{sec}$, Group 2 was given six units of interference in $12 \mathrm{sec}$, and Group 3 was given 12 units of interference in 12 sec.

To minimize error variance, Ss were eliminated if (1) they read a trigram incorrectly, (2) they reported after their trial that a trigram reminded them of a word, initials, formula, etc., at the time they read it, (3) they reported after their trial that they rehearsed the target trigram during the interpolated activity. The $120 \mathrm{Ss}$ used in this experiment do not include Ss who were eliminated for one of these reasons.

After each trial, Ss in Group 2, the group that saw blank cards in the interpolated activity, were asked, "What did you think about as the blank cards were dealt?"

\section{RESULTS AND DISCUSSION}

Recall of the target trigram was scored on a scale of zero to six. Two points were given for a correct letter in its correct position, and one point was given for a correct letter in the wrong position. Mean scores for each group are shown in Table 1. The mean scores of Groups 1 and 2 were compared by a t test and found not to be significantly different. The mean scores of Groups 2 and 3, however, were significantly different $(t=1.75, p<.05)$.

These data support an interference theory of forgetting. That is, memory was significantly impaired when the number of interfering items was doubled, with time held constant; but memory was not significantly impaired when time was doubled, with number of interfering items held constant. This verifies results reported by Murdock (1961), and by Waugh \& Norman (1965), while eliminating sources of ambiguity in these earlier experiments. These results, moreover, support an interference theory of forgetting, even when the target and interfering items are quite similar.

One might object that even though Group 2's score was not significantly lower than Group I's score, it was, in fact, lower. This is not incompatible with interference theory, even though Group 1 and Group 2 experienced the same number of interfering

Table 1 Mean Scores

\begin{tabular}{lcc} 
Treatment & $\begin{array}{c}\text { Mean } \\
\text { Score }\end{array}$ & $\begin{array}{c}\text { Standard } \\
\text { Deviation }\end{array}$ \\
\hline Group 1 & 4.1 & 1.9 \\
Group 2 & 3.7 & 2.4 \\
Group 3 & 2.8 & 2.3 \\
\hline
\end{tabular}


Table 2

Cognitive Activity (Group 2)

\begin{tabular}{lcc}
$\begin{array}{c}\text { Cognitive } \\
\text { Activity }\end{array}$ & Frequency & $\begin{array}{c}\text { Mean } \\
\text { Score }\end{array}$ \\
\hline "Nothing" & 12 & \\
"Rest" & 8 & \\
"Blank" & 3 & \\
"Get set" & 2 & 4.1 \\
\hline Total & 25 & \\
\hline & & \\
"Inhibit response" & 9 & \\
"Finish last add" & 4 & \\
"Look for pattern" & 2 & 3.1 \\
\hline Total & 15 &
\end{tabular}

items. The reason is that Group 2 also experienced blank cards, and there is no way to insure that Ss will not engage in self-initiated interfering activity during blank-card intervals. An attempt was made to measure self-initiated interference by asking Ss in Group

Table 3

Analysis of Errors

\begin{tabular}{lc}
\multicolumn{1}{c}{ Source of Error } & $\begin{array}{c}\text { Number of } \\
\text { Error Letters }\end{array}$ \\
\hline 2nd Practice Trigram & 98 \\
1st Practice Trigram & 33 \\
Other & 10 \\
\hline Total & 141 \\
\hline
\end{tabular}

2 what they thought about during blank card intervals. Results are shown in Table 2.

Responses to this question were classifiable into seven categories, shown in the table. Categories of cognitive activity which are judged to approximate the ideal of no interfering activity are listed in the top part of the table. Categories which are judged to depart from this ideal are listed in the bottom part of the table. As would be expected under an interference theory, Ss who reported self-initiated interfering activity during the blank-card intervals earned lower scores than Ss who reported little or no self-initiated interfering activity. In fact, Group $2 \mathrm{Ss}$ who reported little or no self-initiated interference earned the same mean score as Group 1 Ss.

An error analysis is contained in Table 3. Almost all errors were intrusions of one, two, or three letters from the two trigrams in the practice cards. A recency gradient is obvious in this data-that is, the second practice trigram was the source of more intrusions than the first. Even though Ss were not trying to remember the practice trigrams, and even though practice trigrams were followed by a recall interval much longer than the longest interval used by Peterson \& Peterson (1959), the practice trigrams were available and showed up as intrusions. It seems that more information gets into memory than is often supposed; but when interference is experienced, this information becomes difficult to retrieve.

\section{REFERENCES}

MURDOCK, B. B., Jr. The retention of individual items. Journal of Experimental Psychology, 1961, 62, 618-625.

PETERSON, L. R., \& PETERSON, M. J. Short-term retention of individual verbal items. Journal of Experimental Psychology, 1959, 58, 193-198.

WAUGH, N. C., \& NORMAN, D. A. Primary memory. Psychological Review, 1965, 72, 89-104. 